\title{
POLÍTICAS DE ADAPTAÇÃO FRENTE ÀS MUDANÇAS CLIMÁTICAS GLOBAIS: ESTRATÉGIAS DE GESTÃO PARA AS PRAIAS DO MUNICÍPIO DE MATA DE SÃO JOÃO, LITORAL NORTE DA BAHIA, BRASIL
}

\author{
ADAPTATION POLICIES IN FRONT OF GLOBAL CLIMATE CHANGES: MANAGEMENT \\ STRATEGIES FOR THE BEACHES OF THE MUNICIPALITY OF MATA DE SÃO JOÃO, \\ NORTHERN COAST OF BAHIA, BRAZIL
}

\author{
Jacqueline Lopes de SOUZA, Iracema Reimão SILVA, Rodrigo Alves SANTOS \\ Universidade Federal da Bahia. Instituto de Geociências. Departamento de Oceanografia. Rua Barão de Jeremoabo, s/n, Campus \\ Universitário de Ondina, Salvador - BA. E-mails: jackllopes@hotmail.com; iracemars@yahoo.com.br; rodrigoa20@yahoo.com.br

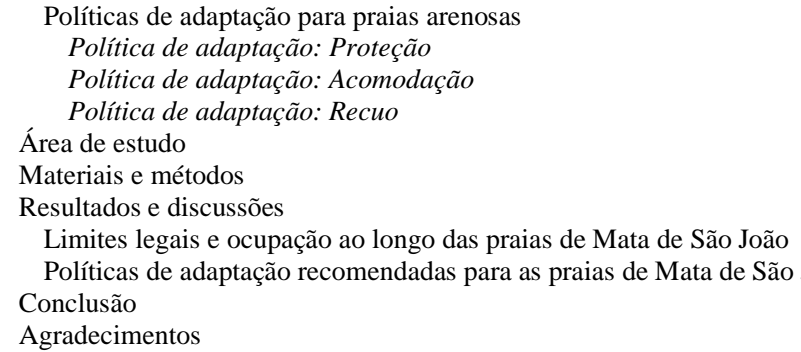

RESUMO - A possibilidade de perda das praias arenosas em decorrência das mudanças climáticas em curso, tem atualmente despertado grandes preocupações. Saber qual a melhor resposta a essas mudanças é fundamental para a manutenção desses ambientes. Desta forma, visando contribuir com a gestão das praias de Mata de São João (BA), na prevenção de futuras perdas econômicas, este estudo tem como objetivo principal analisar as políticas de adaptação mais adequadas para estas praias. As políticas discutidas foram classificadas em três opções de adaptação: proteção, acomodação e recuo. Foram realizadas visitas de campo com caminhadas ao longo de toda a linha de costa de Mata de São João, contabilizando $26 \mathrm{~km}$ de descrição, observação e registros fotográficos. As caminhadas foram realizadas em dois períodos distintos, verão e inverno, e permitiu indicar a política de adaptação mais adequada para cada trecho da área estudada. A baixa ocupação na maior parte da sua linha de costa permite o estabelecimento de faixas de recuo seguindo recomendações do Ministério do Meio Ambiente em aproximadamente 92,8\% da área estudada. Nos trechos com ocupação, as técnicas de proteção como alimentação praial, reabilitação do cordão arenoso e bagwall são as mais adequadas. Essas políticas permitirão o restabelecimento e a continuidade da funcionalidade destas praias.

Palavras-chave: Mudanças Climáticas. Adaptação. Praias. Mata de São João. Bahia.

\begin{abstract}
The possibility of the sandy beaches loss in consequence of the climate changes is worrisome. Knowing what best response the to these changes is critical to maintenance the of these environments. In this way, to contribute with management of the beaches of the municipality of Mata de São João, in the prevention of future economic losses, this study has main objective to analyze the of adaptation policies most appropriate for be these beaches. The policies discussed were classified into three adaptation options: protection, accommodation and retreat. Field visits with walks were made along the entire coastline of Mata de São João, accounting $26 \mathrm{~km}$ of description, observation and photographic records. The hikes were carried out in two different periods, summer and winter, and allowed to indicate the most appropriate adaptation policy for each section the studied area. The low occupancy in most of yours line off coastline allows the establishment of recoil strips following recommendations the Ministry of Environment in approximately 92.8\% of the study area. In the stretches with occupation, protection techniques such beach feeding of the, rehabilitation of the sandy cord and bagwall are the most appropriate. These policies allow the re-establishment and continuity of the functionality of these beaches.
\end{abstract}

Keywords: Climate Change. Adaptation. Beaches. Mata de São João. Bahia.

\section{INTRODUÇÃO}

As praias arenosas constituem-se como um dos ambientes mais dinâmicos da zona costeira e representam um importante elemento de defesa da costa, realizando de forma natural a dissipação e a reflexão da energia de onda que incide sobre elas, protegendo os ecossistemas adjacentes, as atividades recreacionais e turísticas e os habitats de diferentes espécies vegetais e animais (Hoefel
\& Klein, 1998; Muehe, 1998, 2004; Souza et al., 2005; IH-Cantábria, 2013).

Todavia, algumas praias se encontram seriamente ameaçadas pelas mudanças climáticas em curso. A elevação do nível do mar e a possibilidade de um aumento na ocorrência e intensidade de eventos extremos tendem a iniciar ou agravar processos de erosão e inundação 
costeira (Muehe \& Neves, 1995; Nicholls \& Leatherman, 1995; Nicholls et al., 1995; Leatherman et al., 2000; Nicholls, 2004; Nicholls \& Tol, 2006; Neves \& Muehe, 2008).

Segundo Slangen et al. (2014) a subida do nível do mar ocasionada em função da expansão térmica da água dos oceanos é um dos indicativos mais relevantes de mudanças climáticas globais e já é possível ser percebida em várias regiões do planeta, ocorrendo em cada uma delas em diferentes taxas e consequências. Assim, a sociedade deve aprender a viver com um litoral em rápida evolução, que está cada vez mais propenso a fenômenos de erosão e inundação (Nicholls \& Leatherman, 1995).

Dados divulgados no Congresso Internacional sobre Mudanças Climáticas ocorrido na Dinamarca no ano de 2009 e estudos desenvolvidos nos últimos anos, mostram que o aumento do nível do mar está acelerado e deverá agravar durante o próximo século (Rahmstorf et al., 2007; Vellinga, et al., 2009; Nicholls \& Cazenave, 2010; IPCC, 2014; Joughlin et al., 2014; Slangen et al., 2014; Carrasco et al., 2016). De acordo com estimativas feitas pelo Intergovernmental Panel on Climate Change IPCC (2014) o nível global do oceano aumentará em torno de $79 \mathrm{~cm}$ até 2100 . Litorais que já sofre com retração ficarão ainda mais propensas ao recuo da linha de costa (Germani et al., 2015). Estas áreas, na sua grande maioria urbanizada, terão a segurança da população, suas infraestruturas e propriedades ameaçadas.

Análises recentes apontam que cada centímetro de elevação do nível do mar é acompanhado por uma perda de cerca de um metro da faixa de areia da praia, fato que tem preocupado bastante os pesquisadores, uma vez que cerca de $70 \%$ das praias arenosas do mundo já se encontram em retração de acordo com dados do International Bank for Reconstruction and Development - IBRD (Leatherman et al., 2000). O IPCC (2014) observou que, com o mar a um nível de altura em torno de 50 centímetros a 1 metro, as praias perderão partes significativas das suas áreas recreacionais, além de serem constantemente afetadas por tempestades e inundações. Mesmo as praias menos vulneráveis terão sua faixa de areia reduzida (Nicholls, 2004; Nicholls \& Tol, 2006).

Neste sentido, políticas de adaptação têm sido adotadas, principalmente à medida que os impactos reais e potenciais das alterações climáticas se tornam evidentes e por serem as zonas costeiras um dos ambientes naturais mais densamente povoados e dinâmicos do planeta. De acordo com Nordstrom (2010), estudos realizados pela United Nations Conference on Environment and Development - UNCED mostraram que até 2020 mais de $60 \%$ da população mundial deverá residir a menos de $60 \mathrm{~km}$ da costa. Atualmente cerca de um quarto da população brasileira vive na zona costeira, representando um contingente de aproximadamente 42 milhões de habitantes, distribuídos em aproximadamente $324.000 \mathrm{~km}^{2}$.

No Brasil, os municípios litorâneos aumentam ainda mais a sua vulnerabilidade a eventos relacionados ao clima em função da falta de planejamento territorial para a ocupação (Ribeiro, 2008). Para Pereira \& Coelho (2013), a presença de pessoas ou bens em ambientes vulneráveis gera situações de risco à vida ou às propriedades, evidenciando a necessidade de políticas de adaptação. Em litorais urbanizados a migração transversal (da praia rumo ao continente), em consequência da erosão costeira, é impedida pela existência de construções, resultando no desaparecimento da região de póspraia e na perda de área recreativa (Souza, 2009). Assim, as variações no comportamento da linha de costa representam um importante fator condicionante da funcionalidade praial.

As praias do município de Mata de São João, litoral norte da Bahia, são importantes destinos turísticos que tem experimentado nas últimas décadas um intenso e constante processo de exploração dos seus recursos naturais para fins recreacionais. A ocupação cada vez mais próxima da linha de costa associado à falta de um plano de uso deste litoral poderá resultar em problemas ambientais e em diversos prejuízos econômicos e sociais. Além disso, a possibilidade de uma maior incidência de eventos climáticos extremos ao longo deste litoral (IPCC, 2007; Diniz \& Resende, 2014; Marengo, 2008) pode representar uma grave ameaça ambiental e social.

Ao longo deste litoral o turismo e as práticas recreativas, sustentadas em função das praias, se constituem, muitas vezes, no principal fator de desenvolvimento econômico local e regional. Em razão dessas ameaças, faz-se necessário o desenvolvimento e a aplicação de políticas e ações que contribuam para a proteção e adaptação destes ambientes (Mycoo, 2014). 
Desta forma, visando contribuir com uma melhor gestão destas praias, na prevenção de futuras perdas econômicas, este estudo tem como objetivo principal analisar as políticas de adaptação mais adequadas para serem implementadas nas praias do município de Mata de São João. Estudos que abordam esta temática tornam-se cada vez mais necessários frente às incertezas relacionadas às mudanças climáticas globais.

\section{Políticas de adaptação para praias arenosas}

A retirada da população de áreas litorâneas resolveria o problema de recuo da linha de costa, pois ofereceria espaço suficiente para o avanço do mar e o restabelecimento de novos perfis praiais (Linham \& Nicholls, 2010, 2012; Mycoo, 2014). Mas tal retirada é improvável, uma vez que a grande maioria dos governos locais e dos proprietários de terras defendem outras medidas de respostas (adaptação), mesmo com a previsão de uma provável elevação do nível do mar.

Assim, a especulação imobiliária é uma das principais razões pelas quais políticas de adaptação vêm sendo constantemente criadas, uma vez que os elevados investimentos nas praias arenosas urbanizadas exercem pressões para que se mantenha a situação estabilizada (Nordstrom, 2010).

Segundo o documento Coastal Zone Management Strategy - CZMS, desenvolvido pelo Intergovernmental Panel on Climate Change IPCC (Dronkers et al., 1990), proteção, acomodação e recuo são os três principais tipos de políticas de adaptação que podem ser adotadas em resposta a subida do nível do mar e a ocorrência de tempestades, com a finalidade de comtrolar erosão e possíveis inundações (Figura 1).

Nível Atual do Mar

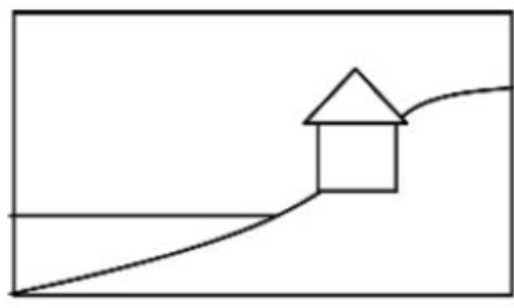

Proteção

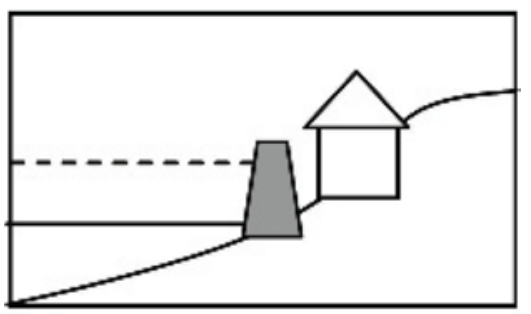

Estabilizar a linha de costa, restaurando a função de proteção das praias

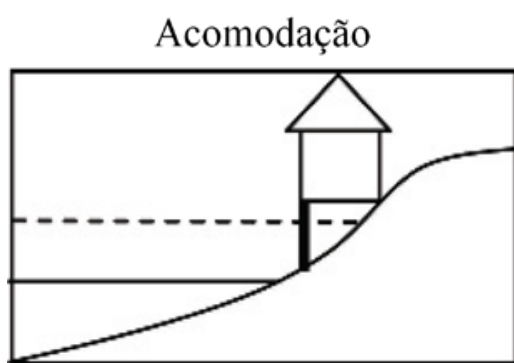

Acomodar as estruturas que estão em áreas vulneráveis aos novos métodos de construção, uso e ocupação

Figura 1 - Esquema ilustrativo das três principais políticas de adaptação para as zonas costeiras. A linha tracejada representa o aumento do nível do mar e a cor mais clara na imagem, indica áreas antes habitadas (adaptado de Linham \&Nicholls, 2010).

Estas políticas de adaptação podem ser implementadas através de uma série de técnicas, por exemplo, obras de engenharia costeira, normas de construções e estabelecimento de faixas de recuo (Tabela 1) (Dronkers et al., 1990; Mycoo, 2014).

\section{Política de adaptação: Proteção}

Esta política envolve técnicas adaptativas que tem a função de atuar no balanço do transporte sedimentar controlando a erosão, estabilizando ou ampliando a linha de costa, restaurando a função de proteção das praias e protegendo as áreas adjacentes contra inundações de ondas de tempestades. As técnicas escolhidas devem sempre levar em consideração as especificações de cada praia, como a dinâmica, o balanço sedimentar, o transporte litorâneo, a evolução histórica da linha de praia, os regimes de ventos, de marés, de ondas e das correntes marítimas (Dronkers et al., 1990; Linham \& NIcholls, 2010, 2012; Mycoo, 2014). Envolvem, por exemplo:

- Paredão e Revestimento Costeiro: estruturas erguidas paralelas à linha de costa, com a finalidade de fixar o limite terra/mar e evitar o 
recuo da praia. Implementados em uma grande parte das costas arenosas do mundo, esta técnica consiste em estabilizar os limites da praia, ao longo da linha de costa que não é adequadamente protegida por esta praia. A estabilidade da estrutura se deve a capacidade da mesma em dissipar e resistir à energia das ondas. As ondas quando refletem sobre a estrutura criam turbulências e suspendem uma grande quantidade de sedimentos, tornando a sua base mais susceptível a erosão e desestabilização (Linham \& Nicholls, 2010). Um exemplo de revestimento costeiro que vem sendo atualmente implementado no Brasil, é o Bagwall, que utiliza geoformas, para conter o avanço do mar e estabilizar a linha de costa. Sua estrutura física ajuda a dissipar a energia das ondas sem transferir o processo erosivo para áreas adjacentes, promovendo a engorda natural da praia (Saathoff, 1994, 1995). Assim, desde que sejam devidamente projetadas, estas construções desempenham alta proteção contra as ações de ondas mais severas, sendo capazes de evitar erosão e inundações no período de eventos meteorológicos mais intensos (Neves \& Muehe, 2008; Van Bentum et al., 2012).

- Alimentação Praial: técnica de adaptação implementada essencialmente em praias arenosas para controlar a erosão costeira e também reduzir impactos de inundação por ondas de tempestades (Campbell \& Benedet, 2006; Speybroeck et al.,
2006; Nordstrom, 2010). Sua técnica consiste na adição artificial de sedimento de qualidade adequada para uma área de praia que tem um déficit de sedimentos, mantendo a praia em uma largura apropriada para absorver a energia das ondas e proteger a linha de costa e as áreas adjacentes (Campbell \& Benedet, 2006; Linham \& Nicholls, 2010; Nordstrom, 2010).

A relevância da alimentação praial vem da dissipação da energia das ondas. Uma praia dissipativa é larga e superficial, enquanto uma praia refletiva é íngreme e estreita obtendo pouca diminuição da energia das ondas na face da praia. Assim, o objetivo da alimentação praial é transformar uma praia de erosão e reflexão em uma praia mais ampla e dissipativa, o que resultará na atenuação da energia das ondas e na diminuição da erosão (Dronkers et al., 1990; Speybroeck et al., 2006; Linham \& Nicholls, 2010). A alimentação artificial é altamente valorizada em praias localizadas em áreas urbanas onde existe a necessidade de recreação e de proteção das construções civis. É reconhecida como uma técnica muito eficaz de adaptação e é utilizada em várias partes do mundo para controlar a erosão e restabelecer a função praial (Campbell \& Benedet, 2006; Houston \& Dean, 2016). Cabe destacar, que como se trata de um ambiente altamente dinâmico, a eficiência da técnica se deve a constante realimentação.

Tabela 1 - Principais técnicas de adaptação recomendadas para praias arenosas, de acordo com o Documento Estratégia de Gestão da Zona Costeira desenvolvido pelo IPCC (Dronkers et al., 1990).

\begin{tabular}{|c|c|c|}
\hline \multicolumn{2}{|c|}{ Técnica adaptativa } & Finalidade \\
\hline \multirow{3}{*}{ Proteção } & Paredão e revestimento & Estabilizar a linha de costa \\
\hline & Alimentação praial & $\begin{array}{l}\text { Controlar a erosão costeira } \\
\text { Controlar inundação (secundário) }\end{array}$ \\
\hline & Construções de dunas e cordões arenosos & Barreira de proteção natural \\
\hline \multirow{2}{*}{ Acomodação } & $\begin{array}{l}\text { Estabelecer padrões de construção destinados } \\
\text { à área litorânea }\end{array}$ & Permitir a Continuidade do uso e ocupação \\
\hline & $\begin{array}{l}\text { Monitoramento sistemático e contínuo das } \\
\text { praias arenosas }\end{array}$ & $\begin{array}{l}\text { Identificar e prevenir ameaças com } \\
\text { antecedência }\end{array}$ \\
\hline Recuo & Estabelecer faixa de recuo & Restringir a ocupação em áreas vulnerávei \\
\hline
\end{tabular}

Construções de Dunas e Cordões Arenosos: envolve a colocação de sedimentos e sua remodelação. É frequentemente realizada em conjunto com a alimentação de praias e desempenha uma importante barreira de proteção contra ação de ondas e marés de tempestades. As dunas e os cordões arenosos ocorrem naturalmente ao longo da maioria das costas arenosas, mas o manejo inadequado e a não recuperação das áreas com déficit sedimentar acaba degradando integralmente esta barreira natural de proteção (Linham \& Nicholls, 2010; Nordstrom, 2010).

Ao reabilitar dunas e cordões arenosos, se faz necessário a colocação de coberturas vegetais sobre as dunas e os cordões arenosos para prevenir a migração da areia para o interior do continente, esgotando o sistema praial 
(Nordstrom, 2010). Tanto a alimentação artificial de praias, como a construção ou reabilitação de dunas e cordões arenosos, são reconhecidas como uma importante técnica adaptativa em reposta a erosão costeira (Campbell \& Benedet, 2006).

\section{Política de adaptação: Acomodação}

Acomodação é uma política de adaptação que permite a população costeira continuar ocupando áreas vulneráveis, desde que sigam determinadas exigências para lidar com os efeitos ocasionados pela subida do nível do mar e a ocorrência de ondas de tempestades. Esta política exige planejamento avançado e continuo, além de mudanças no uso e ocupação das praias. As técnicas de adaptação que serão discutidas a seguir envolvem:

- Estabelecer padrões de construção destinados à área litorânea: esta técnica adaptativa consiste em estabelecer padrões de construção que tornem as estruturas de áreas vulneráveis a subida do nível do mar, mais resistentes e capazes de suportarem processo de erosão severa e possíveis inundações ocasionados por ondas e marés de tempestades. A principal finalidade da técnica é garantir a segurança e o bem estar das pessoas que usam e ocupam estas praias e permitir que a área afetada continue a ser desenvolvida (Linham \& Nicholls, 2010). Muitos países já possuem padrões de construção destinados às áreas litorâneas. O código de construção do Caribe é referência mundial e seu modelo é usado por vários países no ordenamento de suas praias. Nos Estados Unidos as normas de construções desenvolvidas para áreas vulneráveis à inundação, também são constantemente aplicadas para as construções localizadas em suas praias. Estas normas consistem em elevar as estruturas a uma altura adequada, proporcionando proteção e resistência aos efeitos de ondas e marés (Linham \& Nicholls, 2010; FEMA, 2011; Aerts \& Botzen, 2011).

- Monitoramento sistemático e contínuo das praias arenosas: como se trata de um ambiente extremamente dinâmico, o monitoramento sistemático e contínuo das praias arenosas é considerado uma importante técnica de gestão das áreas litorâneas, pois permite identificar com antecedência a ocorrência de erosão e sua possível prevenção (Leatherman et al., 2000). Existem diferentes ferramentas que podem auxiliar o monitoramento mais adequado das praias arenosas. O governo brasileiro num esforço para tentar minimizar os impactos da erosão costeira e propor soluções a curto, médio e longo prazo, criou o projeto denominado Transferência de Metodologias e Ferramentas de Apoio à Gestão da Costa Brasileira. Este projeto tem como principal ferramenta o Sistema de Modelagem Costeira (SMC), desenvolvido pelo IH-Cantábria e adaptado para o litoral do Brasil. Esta é uma ferramenta composta por um conjunto de metodologias e modelos, que permitem estudar os processos costeiros e quantificar as variações sofridas pelas praias em decorrência de eventos naturais e humanos (GIOC, 2003; IHCantabria, 2013).

\section{Política de adaptação: Recuo}

A faixa de recuo é uma técnica que restringe a ocupação das áreas de risco estabelecendo faixa de recuo para a ocupação. Geralmente é adotada uma distância para uma determinada característica costeira dentro do qual todos ou certos tipos de desenvolvimento são proibidos (Muehe, 2004; Mycoo, 2006; Linham \& Nicholls, 2010).

Muitos países têm estabelecido faixas de recuo, tanto para manter as características naturais das suas praias, como para prevenir perdas materiais futuras em decorrência da erosão costeira (Muehe, 2004). Segundo Muehe (2001), no Brasil uma faixa de recuo de aproximadamente 100 a 200 metros, seria o ideal para que fenômenos como erosão e inundação decorrentes de eventuais tempestades não venha a prejudicar as áreas adjacentes.

\section{ÁREA DE ESTUDO}

O município de Mata de São João está localizado no Litoral Norte do estado da Bahia, a cerca de $70 \mathrm{~km}$ de Salvador, e apresenta uma faixa litorânea com aproximadamente $26 \mathrm{~km}$ de extensão, onde estão inseridas as praias de Praia do Forte, Imbassaí, Santo Antônio e Sauípe (Figura 2).

As suas praias apresentam características bastante diversificadas, tanto do ponto de vista natural como da ocupação antrópica, o que se expressa como um importante recurso para o desenvolvimento das atividades turísticas, de recreação e de lazer.

A Praia do Forte tem aproximadamente $11,5 \mathrm{~km}$ de extensão e sua faixa de areia possui, em média, 26m de largura no período de baixa 
mar. É o principal destino turístico do munícipio e seus atrativos naturais, culturais e históricos aliados a uma infraestrutura de hotéis, resorts, restaurantes e barracas de praia, atraem um enorme contingente de turistas durante todo o ano. Alguns trechos da praia são protegidos da ação de ondas pela presença de bancos de recife de coral que estão emersos ou paralelos à praia. $\mathrm{O}$ perfil praial apresenta em média baixa declividade $\left(<7^{\circ}\right)$ e granulometria composta por areia grossa a média. Seu limite Sul, que também representa o limite entre os municípios de Mata de São João e Camaçari, é delimitado pelo rio Pojuca.

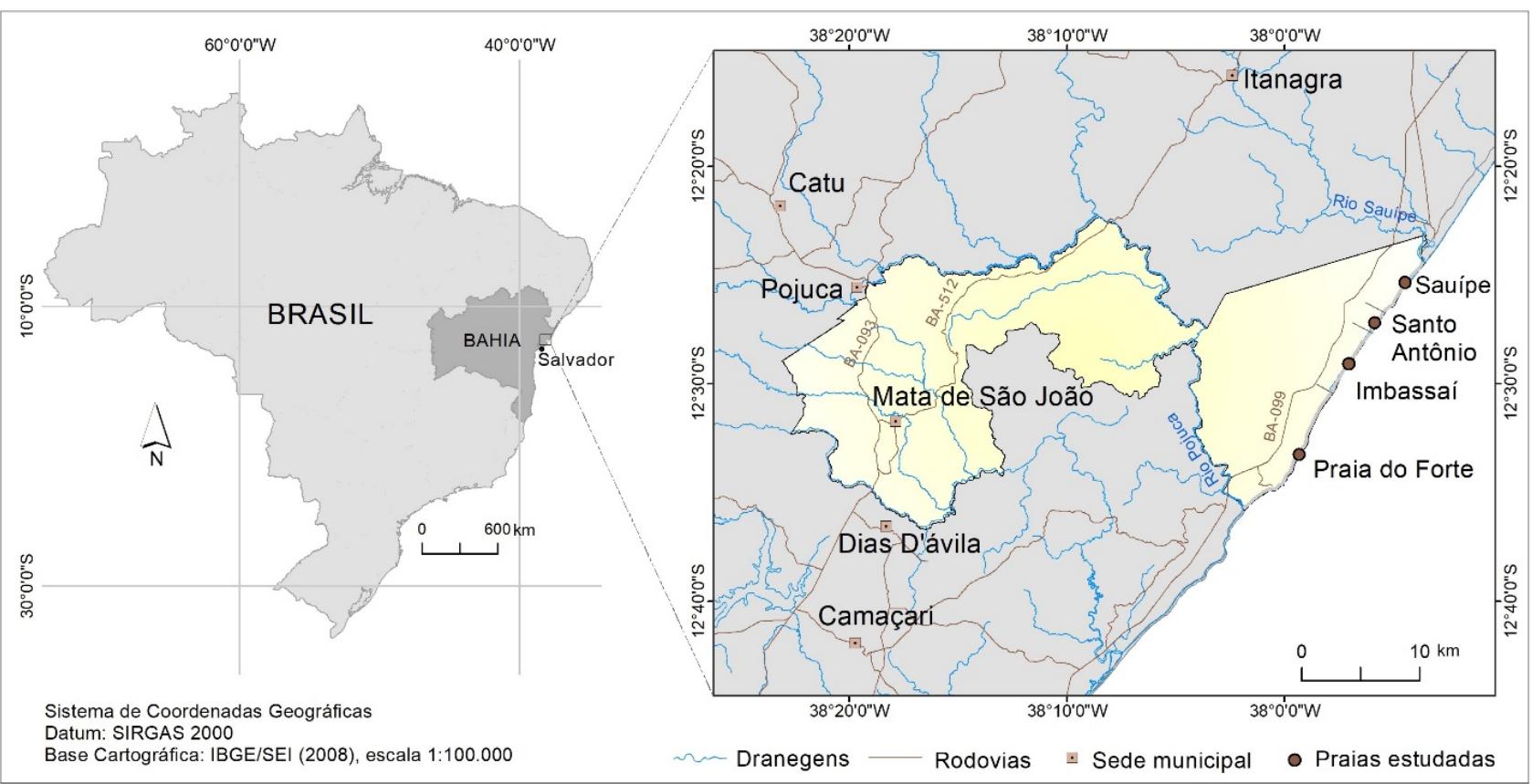

Figura 2 - Mapa de localização das praias de Praia do Forte, Imbassaí, Santo Antônio e Sauípe, localizadas no munícipio de Mata de São João. Fonte: IBGE, 2010.

A praia de Imbassaí é a segunda maior praia da área de estudo, com 6,5km de extensão e largura máxima da faixa de areia em períodos de baixa mar em torno de 35m. No seu limite Sul, onde fica localizado a desembocadura do rio Imbassaí, limite entre a Praia do Forte e a Praia de Imbassaí, é comum à presença de afloramentos de rochas do embasamento cristalino. $\mathrm{O}$ seu perfil praial apresenta baixa declividade $\left(<6^{\circ}\right)$, com granulometria composta por areia média.

Santo Antônio é a praia do munícipio de Mata de São João que mais mantêm as suas características naturais, um campo de dunas ainda preservado separa a praia da vila e impede a ocupação da sua linha de costa. Com quase $2 \mathrm{~km}$ de extensão, sua faixa de areia possui em média 40 a $64 \mathrm{~m}$ de largura, aparecendo um amplo terraço de maré baixa. Em alguns pontos o cordão dunar recebe diretamente a energia das ondas ao longo do ciclo de maré. O perfil praial apresenta baixa declividade $\left(<4^{\circ}\right)$ e granulometria composta basicamente por areia média.

A Praia de Sauípe tem aproximadamente $6 \mathrm{~km}$ de extensão e sua faixa de areia possui em média 50m de largura no período de baixa mar. É um dos destinos turísticos mais procurados do munícipio, em razão da presença de um complexo hoteleiro a beira mar. Seu cordão dunar não recebe diretamente a energia das ondas ao longo do ciclo de maré, exceção se faz do limite sul da praia, onde fica localizado o Complexo Sauípe. Em alguns trechos é comum a presença de afloramentos de rochas do embasamento cristalino. O perfil praial apresenta baixa declividade $\left(<5^{\circ}\right)$ e granulometria composta por areia média. Seu limite norte, que também representa limite entre os municípios de Mata de São João e Entre Rios, é delimitado pelo rio Sauípe.

O clima da área de estudo é do tipo intertropical, caracterizado como quente-úmido, com temperaturas médias anuais em torno de $25^{\circ} \mathrm{C}$ e precipitação pluviométrica em torno de $1.600 \mathrm{~mm}$ anuais (INMET, 1992). Os ventos dominantes são de Sudeste (SE), registrando-se no verão ventos de Leste (E) e Nordeste (NE) (SEMARH, 2003).

Seus solos são essencialmente podzólico vermelho-amarelo, glei húmico, areias quartzosas, areias quartzosas marinhas, e solos indiscriminados de mangue (Silva et al., 1981). O clima, aliado às condições de fertilidade do solo, favorecem o 
desenvolvimento de tipologias vegetacionais costeiras como, Mata Atlântica, mangues e restingas. Os rios Pojuca, Imbassaí e Sauípe que desembocam no município de Mata de São João são considerados de baixa vazão (Bittencourt et al., 2010).

Geologicamente, o município de Mata de São João está situado sobre os depósitos semiconsolidados da Formação Barreiras de idade Miocênica, rochas sedimentares mesozóicas e embasamento cristalino (Martin et al., 1980; Dominguez et al., 2009). Em toda sua linha de costa, estão presentes os depósitos quaternários, representados pelas dunas e depósitos flúviolagunares, além dos terraços marinhos pleistocênicos e holocênicos e de um cordãoduna (Bittencourt et al., 1979; Martin et al., 1980; Dominguez et al., 2006; Esquivel 2006; Dominguez et al., 2009; Bittencourt et al., 2010). Estão presentes também, em alguns trechos de suas praias bancos de arenito de praia e recifes de corais (Martin et al., 1980; Dominguez et al., 1996; Leão \& Kikuchi, 1999; Bittencourt et al., 2010).

Sua morfologia é homogênea, apresenta poucas alterações em termos topográficos o que não ocasiona grandes alterações em seu arcabouço geomorfológico. Os locais que apresentam maiores elevações são as áreas nas quais estão presentes os depósitos semi-consolidados da Formação Barreiras. A planície costeira, que faz parte deste domínio geomorfológico, possui um modelado aplainado em decorrência dos processos geológicos de oscilação do nível relativo do mar, que originou os depósitos marinhos e as feições onduladas dunares, decorrentes da remobilização de sedimentos arenosos durante períodos de climas acentuadamente mais áridos que os atuais (Nunes et al., 1981; Esquivel, 2006).

A plataforma continental da área estuda é uniforme, estreita e possui forte gradiente, suas isóbatas possuem pequenas irregularidades, sendo aproximadamente paralelas entre si e a linha de costa, apresentando linha de quebra em torno de 50m (França, 1979; Vital et al., 2005; Bittencourt et al., 2010). O regime de marés semi-diuro, do tipo meso-marés, com marés de sizígia apresentando amplitude média de 2,8m (França, 1979; Vital et al., 2005; Bittencourt et al., 2010).

\section{MATERIAIS E MÉTODOS}

Seguindo os objetivos do trabalho, foram desenvolvidas as seguintes etapas norteadoras da pesquisa:

Primeira etapa, Trabalho de Gabinete - o estudo consistiu no levantamento e análise da literatura disponível e pertinente ao desenvolvimento da pesquisa.

Foram utilizados como embasamento teórico - metodológico e conceitual deste trabalho, publicações em livros, periódicos e relatórios técnicos-científicos.

Segunda etapa, Levantamento de Campo Foram realizadas visitas de campo com caminhadas ao longo de toda a linha de costa de Mata de São João, contabilizando $26 \mathrm{~km}$ de descrição, observação e registros fotográficos. As caminhadas foram realizadas em dois períodos distintos, verão e inverno e permitiu indicar a política de adaptação mais adequada para cada trecho da área estudada.

Terceira etapa, Espacialização dos Dados - a definição dos limites legais de ocupação se deu a partir da linha de costa, a qual foi traçada seguindo como principal critério a duna frontal (Muehe \& Klumb-Oliveira, 2014). Foi utilizada a operação buffer, no software QGIS 3.4.13, a qual possibilitou a criação de polígonos de 200, 60 e 33 metros em direção ao continente, a partir da linha de costa, correspondendo, respectivamente, aos limites legais estabelecidos por Brasil (2018); Bahia (1989) e Brasil (1988).

Para delimitar as ocupações irregulares foram utilizadas imagens de satélite Sentinel-2 de 17/03/2019 com resolução espacial de 10 metros. O Método de classificação foi o visual, procedendo a vetorização manual das imagens através de polígonos em torno das estruturas fixas de construções dentro dos limites legais preestabelecidos e salvos no formato shapefile para tratamento em ambiente SIG. Essa interpretação foi posteriormente avaliada em campo através de visitas e fotografias, especialmente em locais de dúvida durante o processo de vetorização.

Quarta etapa, Tratamentos dos Dados e Elaboração do Artigo - depois de reunir todos os dados e informações levantadas, entrou-se na última fase do trabalho, que se caracterizou pela organização, sistematização e interpretação dos dados através de tabelas, quadros, mapas, etc., com apresentação das conclusões do diagnóstico, prognósticos sobre a área e recomendações. 


\section{RESULTADOS E DISCUSSÕES}

\section{Limites legais e ocupação ao longo das praias} de Mata de São João

No Brasil, existem três limites legais utilizados para regulamentar, controlar e restringir o uso e a ocupação ao longo do seu litoral (Figura 3). São eles: o limite de 33 metros dos terrenos de marinha (Brasil, 1988), o limite de 50 metros das praias em áreas urbanas e o limite de 200 metros das praias em áreas com processo de ocupação recente (Muehe, 2001; Brasil, 2018). Na Bahia, a Constituição Estadual de 1989 objetivando regular o desenvolvimento da sua zona costeira, definiu uma faixa de recuo de 60 metros de distância, tendo como base para o recuo a linha de preamar máxima (LPM) (Bahia, 1989).

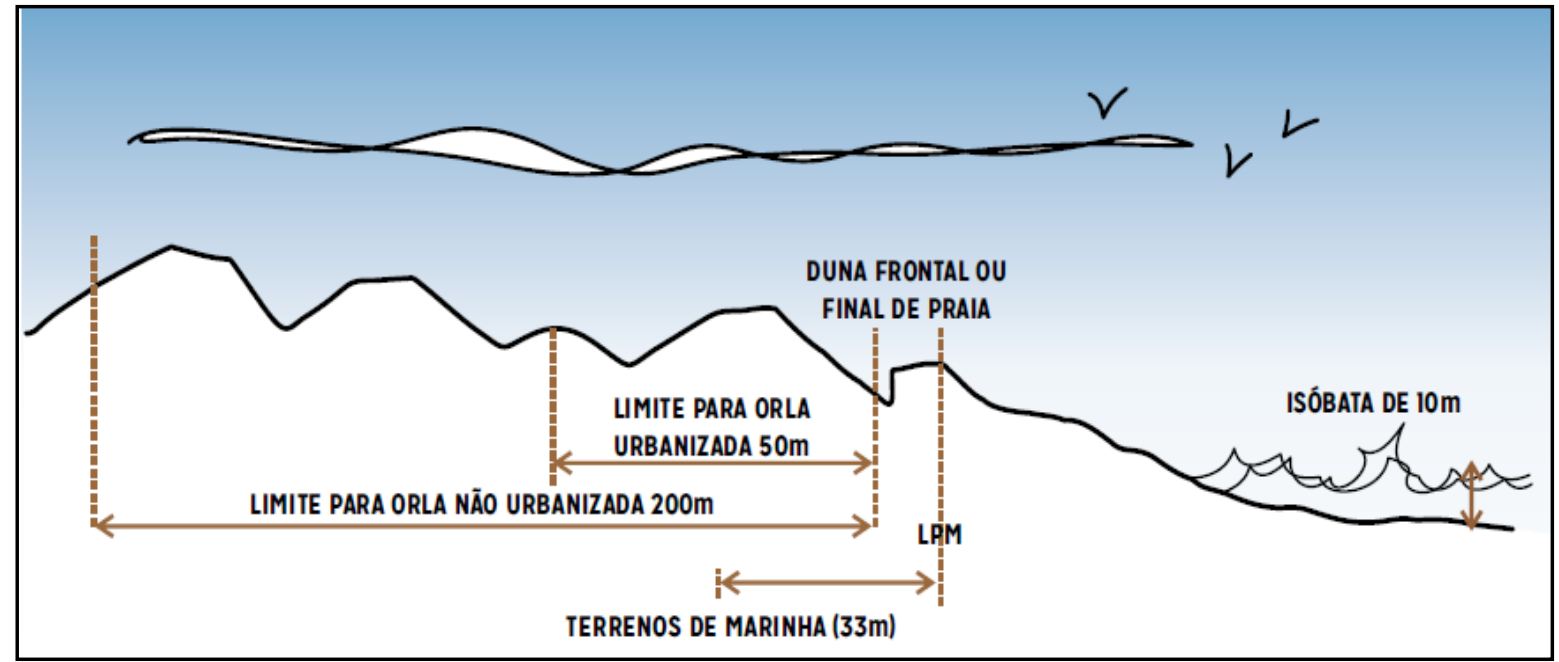

Figura 3 - Desenho esquemático dos três limites que regulam o uso e a ocupação ao longo da linha de costa brasileira (Brasil, 2018).

O processo de ocupação, ao longo das praias de Mata de São João, foi impulsionado, sobretudo, pelo desenvolvimento do turismo de "Sol e Praia”, que conduziu à implantação de diversos empreendimentos recreacionais de grande porte e de alto valor econômico, além da criação de condomínios de luxo e equipamentos turísticos adjacentes à linha de costa.

Todavia, em alguns trechos deste litoral, notase um processo de ocupação, que não levou em consideração as características naturais, a dinâmica costeira local e os limites legais.

Segundo Muehe (1994) e Guerra \& Cunha (2007) o litoral é altamente dinâmico e se caracteriza por instabilidades constantes. A linha de costa e as praias respondem com mudanças de forma e de posição que podem ter consequências econômicas indesejáveis, sobretudo porque a sociedade ocupa espaços que pertencem à dinâmica da natureza.

A medida que o processo de ocupação dessa linha de costa for sendo consolidado, a erosão costeira e a degradação dos ecossistemas associados vão se intensificando, uma vez, que os espaços que deveriam ser preservados, foram indevidamente ocupados.

Neste sentido, tomando como referência os limites legais citados anteriormente, pode-se observar que $7,2 \%$ das construções ao longo da linha de costa de Mata de São João estão localizadas a menos de 200 metros das praias (Figura 4) se enquadrando na categoria de construções irregulares de acordo com o Ministério do Maio Ambiente (Brasil, 2018).

Tomando-se como referência limites mais restritivos, observa-se que 9,7\% destas construções estão dentro da área delimitada pela Constituição do Estado da Bahia (60 metros) e 5,6\% estão em terrenos de marinha (33 metros) (Tabela 2).

Analisando a taxa de ocupação individualizada ao longo das praias, observa-se que a Praia do Forte possui os maiores percentuais de ocupação (10,1\%, 4,2\% e 1,9\%), seguido pelas praias de Sauípe (6,3\%, 0,6\% e 0,01\%), Imbasssaí (3,9\%, 1,9\% e 1,8\%) e Santo Antônio (menos de 1\% de ocupação) respectivamente para os limites definidos por Brasil (2018), Bahia (1989) e Brasil (1988) (Tabela 3).

Apesar da taxa de ocupação ao longo desta linha de costa ser relativamente baixa, esses dados, representam um desafio para a gestão costeira de Mata de São João. 

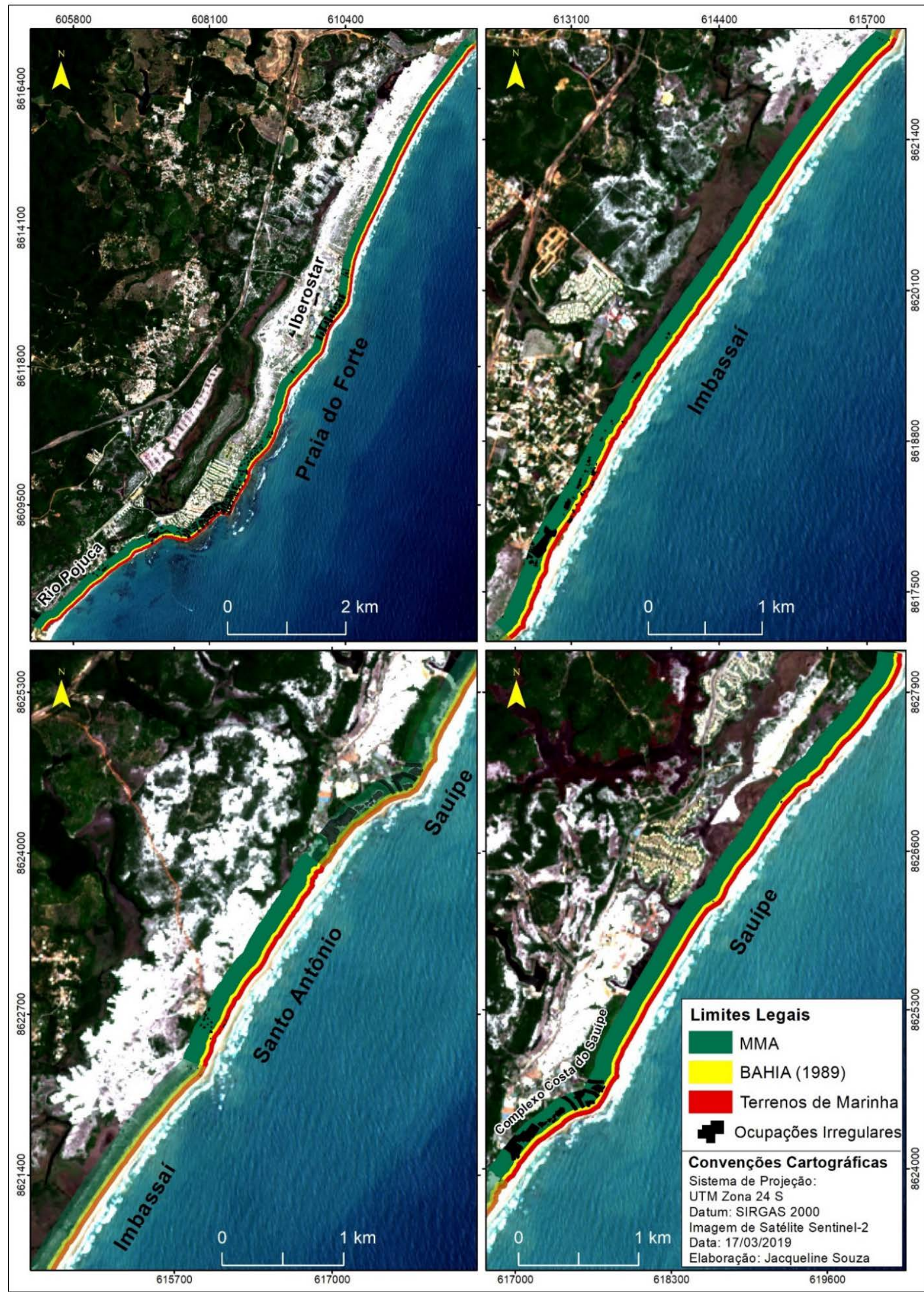

Figura 4 - Delimitação dos limites legais ao longo das praias de Mata de São João (Brasil, 2018; Bahia, 1989; Brasil, 1988). 
Tabela 2 - Taxa de ocupação ao longo das praias de Mata de São João para os limites definidos por Brasil (2018), Bahia (1989) e Brasil (1988).

\begin{tabular}{l|c|c|c}
\hline Limites & Área Legal $\mathbf{( m}^{\mathbf{2}} \mathbf{)}$ & Área Ocupada $\mathbf{( m}^{\mathbf{2}} \mathbf{)}$ & Taxa de Ocupação (\%) \\
\hline MMA & 5316169,0 & 382139,2 & 7,2 \\
\hline Bahia & 1612685,0 & 156780,4 & 9,7 \\
\hline Terrenos de Marinha & 883353,0 & 49374,3 & 5,6 \\
\hline
\end{tabular}

Tabela 3 - Taxa de ocupação ao longo das praias de Praia do Forte, Imbassaí, Sauípe e Santo Antônio de acordo com os limites definidos por Brasil (2018), Bahia (1989) e Brasil (1988).

\begin{tabular}{|c|c|c|c|c|c|c|c|c|c|}
\hline & \multicolumn{3}{|c|}{ Limites Legais $\left(\mathrm{m}^{2}\right)$} & \multicolumn{3}{|c|}{ Área Ocupada $\left(\mathrm{m}^{2}\right)$} & \multicolumn{3}{|c|}{ Taxa de Ocupação (\%) } \\
\hline Praias & MMA & Bahia & Marinha & MMA & Bahia & Marinha & MMA & Bahia & Marinha \\
\hline Praia do Forte & 2576536,0 & 782722,0 & 427255,0 & 260108,0 & 32681,7 & 8111,4 & 10,1 & 4,2 & 1,9 \\
\hline Imbassaí & 1246297,0 & 378834,0 & 208080,0 & 49023,7 & 7356,1 & 3797,1 & 3,9 & 1,9 & 1,8 \\
\hline Santo Antônio & 387941,0 & 116505,0 & 63727,0 & 3507,6 & 640,4 & 394,0 & 0,9 & 0,6 & 0,6 \\
\hline Sauípe & 1105353,0 & 334582,0 & 184250,0 & 69408,8 & 1983,1 & 20,1 & 6,3 & 0,6 & 0,01 \\
\hline
\end{tabular}

Em tempos de Mudanças Climáticas Globais e considerando o cenário mais crítico de elevação do nível do mar, as estruturas localizadas a menos de 200 metros das praias poderão sofrer danos ocasionados por fenômenos como erosão e inundação. Além disso, do total de construções localizadas na área estudada, 5,6\% estão no perfil ativo das praias (Tabela 1), e em situações de preamar já são alcançadas pelas marés. Algumas estruturas já sofrem as consequências dessa proximidade com o mar.

Estudos desenvolvidos ao longo deste litoral (Bittencourt et al., 2010; Silva et al. 2016) mostram que a ocorrência de eventos climáticos extremos implicará em um aumento considerável na frequência e amplitude das ondas e marés meteorológicas, o que poderá desencadear processos de erosão e inundação comprometendo construções e outras estruturas fixas desta praia. Segundo eles, a combinação de eventos de tempestades com marés meteorológicas positivas, marés astronômicas de sizígia e valores extremos de espraiamento de onda, poderá resultar em danos aos ecossistemas costeiros e as propriedades localizadas na porção mais urbanizada desta praia.

Tais estudos apontam evidências crescentes da relação entre mudanças climáticas e perdas econômicas. Assim, a subida do nível do mar e a ocorrência frequente e intensa de tempestades provocadas pelas mudanças climáticas provavelmente aumentarão os problemas ambientais ao longo das praias de Mata de São João.

Segundo Nordstrom (2010), pressões sobre ambientes costeiros são intensificadas pela tendência social de mudar-se para perto da costa, seja em razão do turismo ou até mesmo para evitar conflitos sociais em regiões mais continentais. Muitas localidades costeiras remotas que foram poupadas da urbanização no passado estão agora sofrendo essa pressão. Assim, para evitar prejuízos econômicos, principalmente em áreas costeiras com processo recente de ocupação, se faz necessário o desenvolvimento de estudos mais aprofundados que compreenda melhor o comportamento da linha de costa e apontem com mais precisão suas fragilidades naturais, para que, o processo de tomada de decisões, favoreça o equilíbrio entre o ambiente costeiro, seu uso e ocupação (Nordstrom, 2010).

\section{Políticas de adaptação recomendadas para as praias de Mata de São João}

Entre as três principais políticas de adaptação às mudanças climáticas existentes, a mais indicada para ser implementada nas praias de Mata de São João é a política de recuo (Figura 5). A baixa ocupação na maior parte da sua linha de costa permite o estabelecimento de faixas de recuo seguindo recomendações do Ministério do Meio Ambiente em aproximadamente 92,8\% da área estudada. Tal política permitirá a obtenção do espaço suficiente para o avanço do mar e o restabelecimento de novos perfis praiais, mantendo assim, as características naturais das suas praias e prevenindo possíveis perdas materiais em decorrência de inundações e erosão costeira.

Nos trechos com ocupação (7,2\%), cujo recuo 
é improvável, são sugeridas as políticas de proteção e acomodação (Figura 5). Para os principais trechos com uso recreacional intenso ou alta ocupação no litoral, como nos segmentos próximos à vila e ao Hotel Iberostar, na Praia do Forte, e ao Complexo Hoteleiro Costa do Sauípe, em Sauípe, as técnicas de proteção como alimentação praial, reabilitação do cordão arenoso e bagwall são as mais adequadas para a área de estudo, pois permitirão o restabelecimento e a continuidade da funcionalidade destas praias.
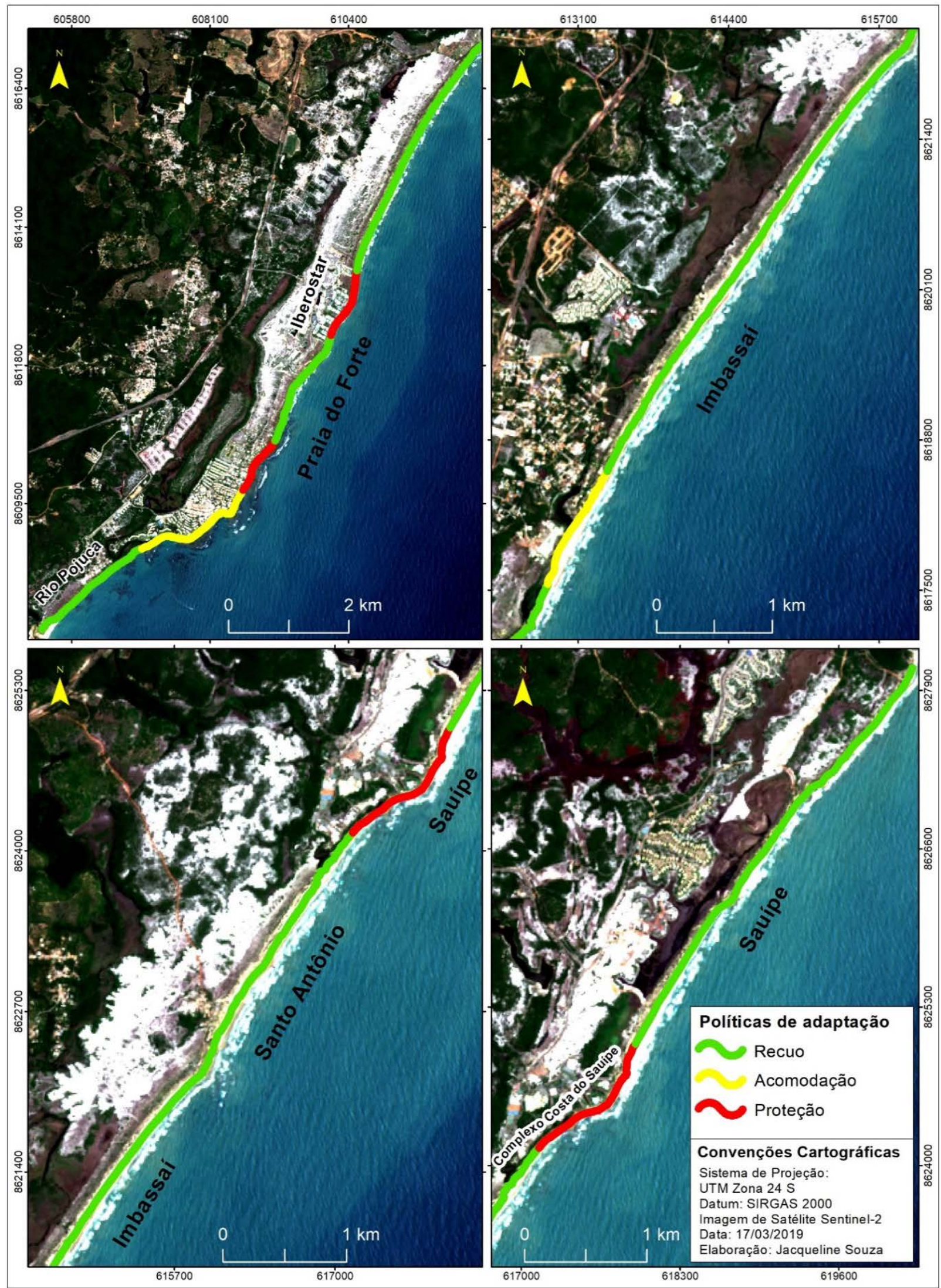

Figura 5 - Políticas de adaptação recomendadas para as praias de Mata de São João. 
Salienta-se ainda a necessidade de atenção especial para o trecho próximo à vila da Praia do Forte devido à ocorrência de recifes de corais. Qualquer intervenção neste trecho, alterando a morfodinâmica local, deve considerar os impactos sobre este ecossistema.

Em relação à política de acomodação, o monitoramento sistemático e contínuo ao logo da linha de costa de Mata de São João, permitirá identificar com antecedência a ocorrência de erosão e inundação e suas possíveis prevenções. Isso é necessário especialmente nos trechos próximos às desembocaduras fluviais, como na porção sul da praia de Imbassaí, com alta mobilidade e vulnerabilidade à erosão.

Nas áreas em que o recuo foi sugerido, não há a necessidade de outra política. A restrição da ocupação destas áreas resolverá o problema de recuo da linha de costa, pois oferecerá espaços suficientes para o avanço do mar e o restabelecimento de novos perfis praias. A política de recuo tem como principal vantagem à resolução integral de problemas de erosão nas áreas litorâneas. O recuo da população abrirá espaço suficiente para o avanço do mar e o restabelecimento de novos perfis praiais, evitando gastos com instalação e manutenção de estruturas de proteção ou acomodação (Dronkers et al., 1990; Linham \& Nicholls, 2010; Nordstrom, 2010). Assim, além de evitar gastos, esta política ajuda a manter a aparência e a dinâmica natural da praia, que muitas vezes, é perdida com a implementação das estruturas de proteção e acomodação. As medidas básicas de recuo são consideradas de baixo custo e podem servir como exemplo para fortalecer outras técnicas adaptativas (Dronkers et al., 1990; Linham \& Nicholls, 2010). A maior desvantagem desta política é a sua inviabilidade em praias já urbanizadas.

Segundo Nordstrom (2010) apesar da grande discussão e propostas de mitigação para amenizar ou solucionar as ameaças das mudanças climáticas, ainda há a necessidade de se buscar uma maior eficácia nas ações para encontrar soluções que tragam benefícios ambientais no controle da erosão costeira. É preciso atingir metas de recuperação de praias com a utilização de um novo conceito de naturalidade, que busquem nas técnicas de adaptação soluções de reconstrução da paisagem natural desses ambientes.

\section{CONCLUSÃO}

Com o aumento da ocupação das áreas costeiras e o quadro atual de Mudanças Climáticas Globais, estudos sobre estratégias de adaptação têm se tornado ferramentas essenciais para a gestão da orla marítima e da zona costeira em várias partes do mundo. A adaptação das praias as ameaças costeiras, sempre se concentrou na proteção da linha de costa através de obras de engenharia como paredões, revestimentos, alimentação de praias, reabilitação de dunas e de cordões arenosos, entre outras. Nas últimas décadas políticas de acomodação e determinação de faixas de recuo estão sendo cada vez mais empregadas em função das mudanças climáticas globais.

Na zona costeira de Mata de São João é possível observar trechos que ainda estão desabitados e trechos que há alguns anos vêm passando por um processo intenso de ocupação. O aumento do nível do mar e a ocorrência frequente e intensa de tempestades ocasionadas por essas mudanças globais poderão afetar significativamente a prática turística e recreacional de suas praias.

As políticas de proteção e acomodação recomendadas para as praias de Mata de São João devem ser aplicadas principalmente nas áreas urbanizadas cujo retorno às condições naturais é improvável. Já a política de recuo deve ser direcionada a adaptação das áreas ainda com processos recentes de ocupação. Assim, a implementação adequada destas políticas adaptativas certamente ajudará a diminuir os impactos nestas praias ocasionados pela subida do nível do mar e a ocorrência de ondas de tempestades. Por fim, associado à política de acomodação, recomenda-se que seja implementado um monitoramento contínuo ao logo da linha de costa, afim de identificar, com antecedência, a ocorrência de erosão e inundação, principalmente nos trechos próximos às desembocaduras fluviais.

\section{AGRADECIMENTOS}

Os autores agradecem ao Conselho Nacional de Desenvolvimento Científico e Tecnológico (CNPq) pelo financiamento da pesquisa e à Coordenação de Aperfeiçoamento de Pessoal de Nível Superior (Capes) pela bolsa de Doutorado. 


\section{REFERÊNCIAS}

AERTS, J.C.J.H. \& BOTZEN, W.J.W. Flood-resilient waterfront development in New York City: Bridging flood insurance, building codes, and flood zoning. Annals of the New York Academy of Sciences, v. 1227, p. 1-83, 2011.

BAHIA. SECRETARIA DE GOVERNO. SECRETARIA DA ADMINISTRAÇÃO. Constituição do Estado da Bahia (1989). Salvador, EGBA, 189 p., 1999.

BITTENCOURT, A.C.S.P.; LIVRAMENTO, F.C.; DOMINGUEZ, J.M.L.; SILVA, I.R. Tendências de longo prazo à erosão costeira num cenário perspectivo de ocupação humana: litoral Norte do Estado da Bahia. Revista Brasileira de Geociências, v. 40, p. 125-137, 2010.

BITTENCOURT, A.C.S.P.; VILAS-BOAS, G. S.; FLEXOR, J. M.; MARTIN, L. Geologia dos depósitos quaternários do litoral do Estado da Bahia. In: H.INDA (ed.) Geologia e recursos minerais do Estado da Bahia. Secretaria de Minas e Energia. Textos básicos, v. 1, p.1-21, 1979.

BRASIL. Constituição 1988. Constituição da República Federativa do Brasil: promulgada em 5 de outubro de 1988. Organização do texto: Juarez de Oliveira. 4. ed. São Paulo: Saraiva, 1990, p.168p., 1990.

BRASIL. Programa Nacional para Conservação da Linha de Costa - PROCOSTA. Ministério do Meio Ambiente, Secretaria de Recursos Hídricos e Qualidade Ambiental, Departamento de Gestão Ambiental Territorial. - Brasília, DF: MMA, 2018.

CAMPBELL, T.J. \& BENEDET L. Beach Nourishment Magnitudes and Trends in the U.S. Journal of Coastal Research v. 1, n. 39, p. 57-64, 2006.

CARRASCO, A.R.; FERREIRA, Ó.; ROELVINK, D. Coastal lagoons and rising sea level: a review. Earth-Science Reviews, n. 154, p. 356-368, 2016.

DRONKERS, J.; GILBERT J. T. E., BUTLER L.W., CAREY J.J., CAMPBELL J., JAMES E., MCKENZIE, C.; MISDORP, R.; QUIN, N.; RIES, K.L.; SCHRODER, P.C.; SPRADLEY, J.R., TITUS, J.G., VALLIANOS, L.; DADELSZEN, V. Strategies For Adaption To Sea Level Rise. Report of the IPCC Coastal Zone Management Subgroup: Intergovernmental Panel on Climate Change. Geneva: Intergovernmental Panel on Climate Change, 148p., 1990.

DINIZ, I.N. \& RESENDE, R. Cartilha: Mudança Global do Clima. Primeira edição, 48 p., 2014.

DOMINGUEZ, J.M.L.; LEÃO, Z.M.A.N.; LYRIO R.S. Litoral Norte do Estado da Bahia. In: SBG, Congresso Brasileiro de Geologia, 39, Roteiro de Excursão, 67 p., 1996.

DOMINGUEZ J.M.L.; BITTENCOURT A.C.S.P.; SANTOS A.; ANDRADE A.C.S.; LAVENÈRE-WANDERLEY A.A.; SILVA I.R.; QUEIROZ I.; FREITAS L.; NASCIMENTO L.; SILVA R. Bahia. In: MUEHE, D. (Coord.). Erosão e Progradação do litoral brasileiro. Brasília: Ministério do Meio ambiente, p. 220-225, 2006.

DOMINGUEZ, J.M.L.; ANDRADE A.C.S.; ALMEIDA A.B.; BITTENCOURT A.C.S.P. The Holocene Barrier Strandplains of the State of Bahia. In: DILLENBURG, S.R. \& HESP, P.A. (Coords) Geology and Geomorphology of Holocene Coastal Barriers of Brazil. Lecture Notes in Earth Sciences, 107, Berlin, Springer-Verlag, p. 253-285, 2009.

ESQUIVEL, M.S. O Quaternário costeiro do município de Conde: implicações para a gestão ambiental. Salvador, 2006. 103 p. Dissertação (Mestrado em Geologia) - Instituto de Geociências, Universidade Federal da Bahia.

FEDERAL EMERGENCY MANAGEMENT AGENCY (FEMA). Coastal Construction Manual: Principles and Practices of Planning, Siting, Designing, Constructing, and Maintaining Residential Buildings in Coastal Areas. US Department of Homeland Security, v. 1, 55 p., 2011.

FRANÇA, A.M.C. Geomorfologia da Margem Continental Leste Brasileira e da Bacia Oceânica Adjacente. Série
Projeto REMAC, v. 7, p. 89-127, 1979.

GERMANI, Y.F.; FIGUEIREDOB, S.A.; CALLIARIB, L.J.; TAGLIANI, C.R.A. Vulnerabilidade costeira e perda de ambientes devido à elevação do nível do mar no litoral sul do Rio Grande do Sul. Journal of Integrated Coastal Zone Management, v. 15, n. 1, p. 121-131, 2015.

GIOC. Reference Document, vol. I: Coastal Hydrodynamics. State Coastal Office-Spanish Environmental Ministry and University of Cantabria, 512 p., 2003.

GUERRA, A.J.T. \& CUNHA, S.B. Geomorfologia - uma atualização de bases e conceitos. 7. ed. Rio de Janeiro: Bertrand Brasil, 2007.

HOEFEL, F.G. \& KLEIN, A.H. Beach Safety Issue at Oceanic Beaches of Central Northern Coast of Santa Catarina, Brazil: Magnitude and Nature. Journal of Coastal Research, n. 26, p. 2-6, 1998.

HOUSTON, J.R. \& DEAN, R.G. Erosional Impacts of Modified Inlets, Beach Encroachment, and Beach Nourishment on the East Coast of Florida. Journal of Coastal Research, v. 32, n. 2, p. 227-240, 2016.

IH-CANTÁBRIA. Ondas: Documento Temático. IHCANTABRIA, Universidad de Cantabria/UFSC/IO-USP, 155 p., 2013.

INSTITUTO BRASILEIRO DE GEOGRAFIA E ESTATÍSTICA (IBGE). Malha Municipal Digital de Setores Censitários do Censo 2010, Shapefile. Disp. em: http://www.ibge.gov.br/home/geociencias/geografia/mapas_do c1.shtm. Acesso em: 25 de julho de 2017.

INSTITUTO NACIONAL DE METEOROLOGIA (INMET). Normais Climatológicas 1961 - 1990. Brasília: INMET, 84 p., 1992.

IPCC - PAINEL INTERGOVERNAMENTAL SOBRE MUDANÇA CLIMÁTICA. Climate Change 2014: Synthesis Report - Contribution of Working Groups I, II and III to the Fifth Assessment Report of the Intergovernmental Panel on Climate Change [Core Writing Team, R.K. PACHAURI AND L.A. MEYER (eds.)]. IPCC, Geneva, Switzerland, 151 p., 2014.

IPCC - PAINEL INTERGOVERNAMENTAL SOBRE MUDANÇA CLIMÁTICA. IV Relatório do IPCC/ONU. Mudança climática 2007: a base da ciência física. Novos Cenários Climáticos. Paris: IPCC/ONU, 24 p., 2007.

JOUGHIN, I.; SMITH, B. E.; MEDLEY, B. Marine ice sheet collapse potentially under way for the thwaites glacier basin, West Antarctica. Science, v. 344, p. 735-738, 2014.

LEÃO, Z.M.A.N. \& KIKUCHI, R.K.P. The Bahian Coral Reefs - from 7000 years BP to 2000 years AD. Ciência e Cultura, v. 51, p. 262-273, 1999.

LEATHERMAN, S.P.; ZHANG, K.; DOUGLAS, B.C. Sea level rise shown to drive coastal erosion. Eos, v. 81, n. 6, p. 55-57, 2000.

LINHAM, M.M. \& NICHOLLS, R.J. Adaptation technologies for coastal erosion and flooding: a review. Proceedings of the Institution of Civil Engineers. Maritime Engineering, v. 165, n. 3, p. 95-111, 2012.

LINHAM, M.M. \& NICHOLLS, R.J. Technologies for Climate Change Adaptation: Coastal Erosion and Flooding. Roskilde, Denmark, UNEP Ris Centre on Energy, Climate and Sustainable Development, 150 p., 2010.

MARENGO, J.A. Água e mudanças climáticas. Estudos avançados, v. 22, n. 63, p. 83-96. 2008.

MARTIN, L.; BITTENCOURT, A.C.S.P.; VILAS BOAS, G.S.; FLEXOR J.M. Texto Explicativo para o Mapa Geológico do Quaternário Costeiro do Estado da Bahia. CPM/SME, Bahia, Brasil, 20 p., 1980

MUEHE, D. \& NEVES, C.F. The implications of seal-level rise on the Brazilian coast: a preliminary assessment. Journal of Coastal Research, v. 15, p. 54-78, 1995. 
MUEHE, D. Critérios morfodinâmicos para o estabelecimento de limites da orla costeira para fins de gerenciamento. Revista Brasileira de Geomorfologia, v. 2, n. 1, p. 35-44, 2001.

MUEHE, D. Definição de limites e tipologias da orla sob os aspectos morfodinâmicos e evolutivos. In: Subsídios para um projeto de gestão. Ministério do Meio Ambiente, Ministério do Planejamento, Orçamente e Gestão. Brasília: MMA, p. 1130, 2004.

MUEHE, D. Geomorfologia Costeira. In: CUNHA, D. S. E GUERRA, T. J. A. (Orgs.). Geomorfologia: uma Atualização de Bases e Conceitos. Rio de Janeiro: Bertrand Brasil, 1994.

MUEHE, D. O litoral brasileiro e sua compartimentação. In: GUERRA, A.J.T. \& CUNHA S.B. (Coords) Geomorfologia do Brasil. Bertrand Brasil, p. 273-349, 1998.

MUEHE, D.; KLUMB-OLIVEIRA, L. Deslocamento da linha de costa versus mobilidade praial. Quaternary and Environmental Geosciences, v. 5, n. 2, p. 121-124, 2014.

MYCOO, M. Sustainable Tourism Using Regulations, Market Mechanisms and Green Certification: A Case Study of Barbados. Journal of Sustainable Tourism, v.14, n. 5, p. 489511. 2006.

MYCOO, M. Sustainable tourism, climate, change and sea level rise adaptation policies in Barbados. Natural Resources Forum, v. 38, n. 1, p. 47-57, 2014.

NEVES, C.F. \& MUEHE, D. Vulnerabilidades, impactos e adaptação a mudanças do clima: a zona costeira. Parcerias Estratégicas, v. 27, p. 217-295, 2008.

NICHOLLS, R.J. \& CAZENAVE, A. Sea-Level Rise and Its Impact on Coastal Zones. Science, v. 328, p.1517-1519, 2010.

NICHOLLS, R.J. \& LEATHERMAN, S.P. The implications of accelerated sea-level rise for developing countries: a discussion. Journal of Coastal Research, v. 14, p. 303-323, 1995.

NICHOLLS, R.J. \& TOL, R.S.J. Impacts and responses to sealevel rise: A global analysis of the SRES scenarios over the twenty-first century. Philosophical Transactions of the Royal Society, v. 364, p. 1,073-1,095, 2006.

NICHOLLS, R.J. Coastal flooding and wetland loss in the 21st Century: changes under the SRES climate and socio-economic scenarios. Global Environmental Change, v. 14, p. 69-86, 2004.

NICHOLLS, R.J.; LEATHERMAN, S.P.; DENNIS, K.C.; VOLONTÉ, C.R. Impacts and responses to sea-level rise: qualitative and quantitative assessments. Jounal of Coastal Research, v. 14, p. 26-43, 1995.

NORDSTROM, K.F. Recuperação de Praias e Dunas. São Paulo: Oficina de Textos, 263p., 2010.

NUNES, B.; RAMOS, V.; DILLIGER, A. Geomorfologia. In: Departamento Nacional da Produção Mineral. Projeto RADAMBRASIL. Folha SD. Salvador: geologia, geomorfologia, pedologia, vegetação, uso potencial da terra. Rio de Janeiro, v. 24, 620 p., 1981.

PEREIRA, C. \& COELHO, C. Mapas de Risco das Zonas Costeiras por Efeito da Ação Energética do Mar. Revista de Gestão Costeira Integrada, v. 13, n. 1, p. 27-43, 2013.

RAHMSTORF, S., A. CAZENAVE, J.A. CHURCH, J.E. HANSEN, R.F. KEELING, D.E. PARKER, R.C.J. SOMERVILLE. Recent climate observations compared to projections. Science, 2007.

RIBEIRO, W.C. Impactos das mudanças climáticas em cidades no Brasil. Parcerias Estratégicas, v. 27, p. 297-321, 2008.

SAATHOFF, F. \& WITTE, J. Use of geotextile containers for stabilizinng the scour embankment at the Eidersperrwerk. Geosynthetics Word, v. 5, n. 1, p. 1-6, 1994.

SAATHOFF, F. \& WITTE, J. Use of geotextile containers for stabilizinng the scour embankment at the Eidersperrwerk. Geosynthetics Word, v. 5, n. 2, p. 1-65, 1995
SEMARH. Projeto de Gerenciamento Costeiro, Gestão Integrada da Orla Marítima no Município do Conde no Estado da Bahia. Diagnóstico Sócio-Econômico e Ambiental do Conde. Ministério do Meio Ambiente, Salvador: Secretaria de Meio Ambiente e Recursos Hídricos. Centro de Recursos Ambientais (CRA), 2003.

SILVA, G.B.; SANTOS, J.H.G.; CORRÊA, P.R.S. Solos. In: Departamento Nacional da Produção Mineral. Projeto RADAMBRASIL. Folha SD. 24 Salvador: geologia, geomorfologia, pedologia, vegetação, uso potencial da terra. Rio de Janeiro: MME, v. 24, 620 p. 1981.

SILVA, I.R.; GUIMARÃES, J.K.; BITTENCOURT, A.C.S.P.; RODRIGUES, T.K.; NETO, G.F.A. Modelagens de Clima de Ondas e Transporte Sedimentar Utilizando o SMC-Brasil: Aplicações para a Praia do Forte, Litoral Norte do Estado da Bahia. Revista Brasileira de Geomorfologia, v. 17, n. 4, p. 743-761, 2016.

SLANGEN, A.B.A.; CHURCH, J.A.; ZHANG, J.A.; MONSELESAN, D. Detection and attribution of globalmean thermosteric sea level change. Geophysical Reseach Letters, v. 41, p. 5951-5959, 2014.

SOUZA, C.R.G. A Erosão nas Praias do Estado de São Paulo: Causas, Consequências, Indicadores de Monitoramento e Risco. In: BONONI, V.L.R. \& SANTOS JÚNIOR, N.A. (coordenadores.) Memórias do Conselho Científico da Secretaria do Meio Ambiente: A Síntese de Um Ano de Conhecimento Científico Acumulado. Instituto de Botânica Secretaria de Meio Ambiente do Estado de São Paulo, São Paulo, p. 48-69, 2009.

SOUZA, C.R.G.; SOUZA FILHO, P.W.M.; ESTEVES, L.S.; VITAL, H.; DILLEMBURG, S.R.; PATCHINEELAM, S.M. \& ADDAD, J.E. Praias arenosas e erosão costeira. In: SOUZA, C.R.G.; SUGUIO, K.; OLIVEIRA, A.M.S.; OLIVEIRA, P.E. (Coords) Quaternário do Brasil. Ribeirão Preto Ribeirão Preto: Ed. Holos, v. 1, p. 130-152, 2005.

SPEYBROECK, J.; BONTE, D.; COURTENS, W.; GHESKIERE, T.; GROOTAERT, P.; MAELFAIT, J.P.; MATHYS, M.; PROVOOST, S.; SABBE, K.; STIENEN, E.W.M.; VAN LANCKER, V.; VINCX, M.; DEGRAER, S. Beach nourishment: an ecologically sound coastal defense alternative? A review. Aquatic Conservation: Marine and Freshwater Ecosystems, v. 16, p. 419-435, 2006.

VAN BENTUM, K.M.; HOYNG, C.W.; VAN LEDDEN, M.; LUIJENGIJK, A.P.; STIVEL, M.J.F. The Lagos coast Investigation of the long-term morphological impact of the Eko Atlantic City project. Jubilee Conference ProceedingsNCK-Days, p. 1-5, 2012.

VELLINGA, P, KATSMAN, C.A., STERL. A. BEERSMA. J.J. Exploring high-end climate change scenarios for flood protection of the Netherlands: International Scientific Assessment, 2009.

VITAL, H.; ESTEVES, L.S; ARAÚJO, T.C.M; \& PATCHNEELAM, S.M. Geologia e Geofísica da Plataforma Continental Brasileira. In: SOUZA, C.R.G.; SUGUIO, K.; OLIVEIRA, A.M.S.; OLIVEITA, P.E. (Coords) Quaternário do Brasil. Holos, Ribeirão Preto - Associação Brasileira de Estudos do Quaternário-ABEQUA, p. 153-175, 2000

Submetido em 26 de abril de 2018 Aceito para publicação em 30 de outubro de 2020 